\title{
LV. On the Wilson-Gerdien theory of thunderstorm electricity
}

\section{George C. Simpson D.Sc.}

To cite this article: George C. Simpson D.Sc. (1909) LV. On the Wilson-Gerdien theory of thunderstorm electricity , Philosophical Magazine Series 6, 17:100, 619-634, DOI: $10.1080 / 14786440408636635$

To link to this article: http://dx.doi.org/10.1080/14786440408636635

曲 Published online: 21 Apr 2009.

Submit your article to this journal $[\pi$

Џll Article views: 4

Q View related articles $\square$

Citing articles: 1 View citing articles $\square$ 
Wilson-Gerdien Theory of Thunderstorm Electricity. 619 Equation (33) like the more exact form (32) has to be solved by trial and error.

The final results are given in the first four columns of the following table, the last four columns are from Prof.Callendar's paper :--

\section{Our results.}

Concentration in grauns per litre.

$\begin{array}{cccc}\text { At bottom. } & \text { At top. } & \text { Diff. } & \text { per cent. } \\ 750 \cdot 6 & 676 \cdot 7 & 73 \cdot 9 & 9 \cdot 85 \\ 660 \cdot 5 & 598 \cdot 6 & 61.9 & 9 \cdot 06 \\ 540 \cdot 4 & 490 \cdot 9 & 49 \cdot 5 & 9 \cdot 16 \\ 420 \cdot 3 & 385 \cdot 2 & 35 \cdot 1 & 8 \cdot 35 \\ 300 \cdot 2 & 278 \cdot 9 & 21 \cdot 3 & 7 \cdot 10 \\ 180 \cdot 1 & 170 \cdot 0 & 10 \cdot 1 & 5 \cdot 61\end{array}$

\section{Prof. Callendar's results.}

\section{Concerstration in} grams per litre.

$\begin{array}{lcrc}\text { At top. At botton. } & \text { Diff. } & \text { per cent. } \\ 760^{*} & 900 & 140 & 15 \cdot 4 \\ 660 & 741 & 81 & 12 \cdot 3 \\ 540 & 600 & 60 & 11 \cdot 1 \\ 420 & 460 & 40 & 9 \cdot 5 \\ 300 & 325 & 25 & 8 \cdot 3 \\ 180 & 193 & 13 & 7 \cdot 3\end{array}$

* It is probable that this number is copied from a misprint in Lord Berkeley's paper on van der Waals' equation (Proc. Roy. Soc. Series A, vol. 1xxix. p. 126).

Prof. Callendar deduces from his results that "the numbers. in the last column appear to indicate a systematic error in the experimental numbers for strong solutions." On comparing the two sets of figures it will be seen that those calculated from the more accurate formula do not bear out Prof. Callendar's deduction.

LV. On the Wilson-Gerdien Theory of Thiunderstorm Electricity. By George C. Simpson, D.Si., Meteorological Department, Government of India*.

I N $1900 \mathrm{Mr}$. C. T. R. Wilson put forward a theory to I account for the electrical phenomena connected with thunderstorms based on his well-known experiments on the condensation of water vapour from supersaturated air upon negative ions. Judging from a number of references to this theory in recent articles in scientific journals it would appear that it has obtained considerable acceptance, both in England and on the continent. It therefore appeared to me desirable that the theory should be subjected to a critical examination, and $I$ propose in this paper to undertake such an examination

* Communicated by the Author 
in order to show that in six important particulars the theory is not capable of accounting for the observed facts.

At the end of the paper in which the results of the experiments already referred to were published, Wilson added the following paragraph $*$ :-

"In order that the results of these investigations should have a direct bearing on the subject of atmospheric electricity, it is necessary to assume that condensation in the atmosphere frequently takes place from the supersaturated condition. There is very little direct evidence of the existence of supersaturation in the atmosphere ; but there is at least an equal lack of evidence against its existence above the lower cloud layers, even as a normal accompaniment of precipitation. That supersaturation occurs in connexion with thunderstorms is beld by V. Bezold and others (Sitzab. Akad. d. Wiss. zu Berlin, 1892)."

This idea, that the electrical effects observed with precipitation might owe their origin to the greater facility with which water vapour is deposited on negative than on positive ions, was eagerly taken up on the continent, and Elster and Geitel considered it so promising that they gave to it a prominent place in their lecture betore the Brunswick Society of Science in April $1900 \dagger$.

The only serious objection to the suggestion came from Mr. Aitken $\ddagger$, who was led to doubt, from his classical researches on the dust of the atmosphere, that "there is such a thing as dust-free air in our atmosphere." To answer Mr. Aitken's objections Wilson wrote a letter to 'Nature' $\$$ in which he developed his idea into a detailed theory, showing how he considered the dust might be entirely removed from air during thunderstorms, and how the separation of the electricity could be supposed to take place. The following summary of this letter, written as far as possible in the original words, may be taken as giving the essential points of Wilson's theory.

If an ascending current of air contains drops of water in the form of cloud-particles these drops will lag behind the air-current to a greater or less extent, according to their sizes. Hence, the air which enters the base of a cumulus cloud will pass amongst the water-drops, and ultimately reach the top. During the passage of the air through the

* Wilson, Phil. Trans. A. 193. p. 307 (1000).

+ Met. Zeit. xvii. pp. 226-231 (1900).

I Aitken, ' Nature,' xli. pp. 514-515 (1900).

$\S$ Wilson, 'Nature,' xlii. pp. 149-151 (1900). 
cloud the innumerable water-drops will act as a kind of filter and remove all the dust-particles from the air. The drops at the top of the cloud will also lag behind the ascending air, and the air between them is likely to be dust-free. "Under these conditions a dust-free layer will be formed above the cloud, and will continually increase in vertical thickness. This layer will be saturated with moisture at its lower edge, above this it will be supersaturated; the amount of supersaturation being greater near its upper limit, and depending on the vertical distance through which the air has risen since escaping from the cloud. Now to produce in air initially saturated the supersaturation (approximately four-fold) necessary to cause water to condense on negative ions, it is sufficient to let the volume of the air increase adiabatically to $1 \cdot 25$ times its initial value ; an expansion which will result from an ascent of the air through a vertical distance of 2,500 metres, if we suppose the air on escaping from the cloud to be at a temperature of $10^{\circ} \mathrm{C}$. (at lower temperatures a smaller elevation would suffice). Thus, when the air in the uppermost layers of the supersaturated stratum has reached a height of about 2,500 metres above the level at which it escaped from the cloud, a sudden change will result; condensation will there take place on the negative ions. The thiclsness of the supersaturated stratum $(i . e$. the vertical distance which the upper surface of this cloud has lagged behind the air) when the condensation on the negative ions begins, may vary greatly ; it may be very small if the drops are small and the ascent of the air rapid; it may amount to nearly the whole 2,500 metres in the case where the drops grow large enough to acquire a velocity relative to the air as great as the upward velocity of the air, so that the upper surface of the cloud has ceased to ascend." The drops which condense on the negative ions at the top of the supersaturated ayer will either fall at once as rain or remain in suspension till they have travelled into regions where the ascending current is insufficient to support them. "In either case, if the drops fall through a supersaturated layer of some thickness, they are likely to reach the ground as negatively charged rain." "The positive ions after being carried up out of reach of the drops formed on the negative ions, will, under the action of the electrical field produced by this separation, tend to travel downward relatively to the air with a velocity of the order of one centimetre per second for a field of 100 volts per metre, as the measurements of Rutherford and others have shown. After being carried beyond the region of ascending air-currents, they will travel downwards towards. 
the earth's surface; but long before reaching it they will become attached to cloud-particles or to the dust-particles of the lower layers of the atmosphere, where the positive charge will accumulate."

At the time when this theory was published it was generally held that Elster and Geitel had satisfactorily explained the normal electrical condition of the atmosphere by their theory of ion absorption; but in 1903 it was shown* that this theory could not be substantiated by experiment. Thus meteorologists were left without any satisfactory theory for the normal electrical phenomena of the atmosphere. It is easy to understand that under these circumstances an attempt should be made to press Wilson's theory into explaining both normal and abnormal electrical phenomena.

This was done with considerable thoroughness by Dr. H. Gerdien in his article on "Der Electrizitatshaushalt der Erde und der unteren Schichten der Atmospbäre," in the Physikalische Zeitschrift $\dagger$. Gerdien introduced no essential differences into the theory, but developed it into greater detail than Wilson had done, and added numerical calculations to show that it was capable of accounting for all the electrical phenomena associated with thunderstorms.

Turning now to our criticism, the theory will be examined first from the electrical side of the problem and then from the meteorological. In the first part of the discussion we shall accept the meteorological conditions supposed by the theory; $i$. e. we will assume the possibility of the formation of a supersaturated stratum above a lower cumulus cloud, and of a condensation layer above in which water vapour is condensed around the negative ions; and then examine whether the electrical effects observed can be supposed to follow from these conditions. Afterwards we will examine the meteorological conditions themselves to find if they are likely to be present during thunderstorms. (1) The first question we will ask is :-

Could a sufficiently rapid separation of electricity take place, under the conditions supposed by the theory, to account for the numerous lightning discharges observed during thunderstorms?

In order to obtain simplicity of treatment we will follow Gerdien in assuming that the processes we are investigating take place in horizontal layers sufficiently near to one ancther in comparison with their lateral extent to be considered as infinite planes. Under such conditions we may assume that

* Simpson, Phil. Mag. [6] vi. p. 589 (1903).

+ H. Gerdien, Phys. Zeit. vi. pp. 647-66 (1905). 
the air which enters any given cross-section at the base of the cloud will rise vertically and leave the region under discussion through a similar area vertically over that through which it entered.

We will now consider the electrical condition of the air at the different stages of its ascent. Before entering the cloud the air may be supposed to contain the mean number of ions per cubic metre found in air under normal conditions. The air enters the cloud with this amount of free electricity, and commences its upward journey through the cloud-particles. We have already agreed that a cloud acts as a filter for dustparticles, and it will be quite as efficient a filter for ions; in fact, direct observations have shown that within a cloud (fog) practically no free ions can be measured. Thus the air which enters the cloud with a large number of free ions will pass out at the top with none, and will commence to travel through the supersaturated stratum with neither dust nor ions. On account of what is generally called natural ionization new ions will at once be formed, and as now there are no waterparticles to catch them they will continue to exist as free ions. But the rate of formation is not rapid. Measurements have been made of the rate at which new ions are being formed in the atmosphere near the earth, and numbers varying between 10 and 50 ions per c.c. per second found ${ }^{*}$.

In the case under consideration it is not likely that the ions would be formed at anything like the rate that they are formed near the earth, if for no other reason than that the radioactive particles which are supposed to be the cause of a great deal of the natural ionization of the air will also have been filtered out in the cloud. Gerdien $\dagger$ has estimated that the rate at which ions form in the region which we are considering is about 10 of each kind per c.c. per second. As, however, I do not wish to err on the side of underestimation, I will assume that the ions are generated at the rate of 25 per c.c. per second.

Now consider an area of $1 \mathrm{sq} . \mathrm{cm}$. at any position on tne upper surface of the lower cloud; the air which passes out of this area will rise vertically and enter the condensation layer through another area of $1 \mathrm{sq} . \mathrm{cm}$. Let us assume that every ion which forms in a cubic $\mathrm{cm}$. of air while passing from the lower cloud to the condensation layer above continues to exist as a free ion; $i$. e. we will entirely neglect the recombination of ions; and let us further assume that

* Schuster, Proc. Man. Lit. and Phil. Soc. vol. xlviii. part ii. p. 1 (1904).

+ Gerdien, l. c. p. 662 . 
every negative ion has water deposited on it when it reaches the condensation layer, and is retained there, while every positive ion passes through. In this way we shall find the absolute maximum rate at which the charge at the condensation layer can increase with naturally ionized air.

Let the upward velocity of the air

$$
=\mathrm{V} \mathrm{cm} . / \mathrm{sec} \text {. }
$$

Then the vol. of air which crosses the sq. cm. under consideration in one second

$$
=\mathrm{V} \text { c.c. }
$$

The time taken for a given small vol. of air to pass from the cloud to the condensation layer, 2,500 metres above

$$
=\frac{2 \cdot 5 \times 10^{5}}{\mathrm{~V}} \mathrm{sec} \text {. }
$$

The number of ions of each sign generated in a c.c. in this time

$$
=\frac{25 \times 2.5 \times 10^{5}}{\mathrm{~V}}=\frac{6.2 \times 10^{6}}{\mathrm{~V}} .
$$

The total number of negative ions which are retained at each sq. cm. of the condensation layer each second

$$
=\frac{6 \cdot 2 \times 10^{6}}{\mathrm{~V}} \times \mathrm{V}=6 \cdot 2 \times 10^{6} \text {. }
$$

Now the charge on $3 \times 10^{9}$ ions is equal to 1 electrostatic unit of electricity.

Hence the maximum rate at which the charge would grow on the condensation layer

$$
=\frac{6 \cdot 2 \times 10^{6}}{3 \times 10^{9}}=2 \times 10^{--3} \text { els. unit }
$$

It is interesting to note that this maximum charge possible is quite independent of the upward velocity of the air, and therefore, from ordinary considerations, independent of the rite of rainfall. This does not mean, however, that if the process as here sketched actually takes place in nature the rate of separation of the electricity would be independent of these factors ; for we have neglected the rate of recombination of the ions, which would be considerable if the rate of rise were so small that it took an appreciable time for the air to pass through the supersaturated stratum ; all factors, however, which we have neglected could only reduce, and not increase, the charge separated at the condensation layer. 
We will now consider how long it will take for electricity accumulating at such a rate at a certain layer in the atmosphere to give rise to a lightning discharge.

We have assumed that the whole of the negative ions are separated at the condensation layer, and that the positive ones are carried up above. Thus we have got a charged layer with the corresponding quantity of electricity in the space above. Let $\sigma=$ the charge on each sq. $\mathrm{cm}$. of this layer at any time $t$ seconds after condensation first started, then the field above the layer will be

$$
\frac{d \mathrm{~V}}{d h}=4 \pi \sigma \frac{\text { els. units }}{\mathrm{cm} .}
$$

or if $\mathrm{V}$ is measured in volts

$$
\begin{aligned}
\frac{d \mathrm{~V}}{d h} & =300 \times 4 \pi \sigma \frac{\text { volts }}{\mathrm{cm} .} \\
& =3.8 \times 10^{3} \sigma \frac{\text { volts }}{\mathrm{cm} .} \text { approx. }
\end{aligned}
$$

Now it was shown above that

$$
\sigma=2 \times 10^{-3} t \text { els. unit. }
$$

Therefore the potential gradient produced would be

$$
\begin{aligned}
\frac{d \mathrm{~V}}{d h} & =3 \cdot 8 \times 10^{3} \times 2 \times 10^{-3} t \frac{\text { volts }}{\mathrm{cm} .} \\
& =8 \mathrm{t} \frac{\mathrm{volts}}{\mathrm{cm} .}
\end{aligned}
$$

That is, the potential gradient above the condensation layer would grow at the rate of 8 volts $/ \mathrm{cm}$. per second. Now air at atmospheric pressure can resist an electric stress of about 30,000 volts per $\mathrm{cm}$; hence it would take $\frac{30,000}{8}$ sec. $=53$ minutes for the potential gradient to grow sufficiently great for a lightning discharge to take place. Thus the first lightning discharge could not, under the favourable conditions we have assumed, occur until nearly an hour after the supersaturated stratum had extended from the cloud to the condensation layer. This first lightning discharge would travel between the condensation layer and the positive charge which had been separated and carried upwards, and would more or less completely conduct away the negative electricity from the portion of the layer affected. In other words, the discharge would neutralize the negative electricity contained in a portion of the layer and destroy the field above it. Thus

Phil. Mag. S. 6. Vol. 17. No. 100. April 1909. 2 U 
a second discharge could not take place until the stress of 30,000 volts per $\mathrm{cm}$. had again been set up by a continuation of the process under discussion, and that would take, as we bave seen, nearly another hour. Thus, if the process were the simple one we have considered, lightning flashes could only take place from any given area of the condensation layer at intervals of about an hour each.

But we must consider if it would not be possible, after the first discharge had taken place, for any other action to come into play which would increase the rate at which the potential gradient could grow, and so make it possible for more rapid discharges to take place.

Gerdien has suggested a "far stronger and more rapidly acting source" of ions than natural ionization. He says*:-

"Such a source must in fact come into action as soon as a single negative ion, within the strong field caused by the separation of the positive and negative ions, is able freely to traverse the 'ionization difference of potential,' and so introduce a disruptive discharge within the field $\dagger$. In this case ionization through ion impact takes place, and in a very short time a degree of ionization is caused which exceeds the ordinary ionization several million times. A part of these newly formed ions will be drawn by the field in to the discharge current, and so neutralize a part of the charge separated by the condensation; the greater part will, however, disappear through recombination. Nevertheless, for a considerable time after the current has passed, a degree of ionization must remain within the region traversed by the discharge, which by far exceeds that present under normal conditions. Thus each disruptive discharge will create a large number of ions which the condensation process can immediately separate so long as the ascending current is present to provide the necessary energy."

But this reasoning is not so conclusive as it would appear on first sight. The discharge considered must take place either upwards or downwards from the condensation layer. In the former case the production of an infinite number of ions would be of no use, for in the region above the condensation layer the air is not supersaturated to a fourfold degree, and so there would be no tendency for water to be deposited on negative ions, no matter how numerous they were. On the other band, if the discharge took place downwards from

* Gerdien, l, c. p. 662.

$\uparrow$ "An irgendeinex Stelle ein negatives Ion die Ionisierungsspannung frei durchlaufen kann und damit die selbstandige Stromung innerhalb
des Feldes einleitet." 
the condensation layer it would of necessity traverse the supersaturated stratum. Now Barus* has shown that whenever ions are formed in dust-free air there is produced at the same time a large number of nuclei, which exist for a long time after the ions have disappeared. As water vapour is very readily deposited on these nuclei fourfold supersaturation is prevented in any air in which they are present, unless the supersaturation is caused by exceedingly rapid rarefaction. Each lightning discharge which passes through the supersaturated layer will produce a large number of these efficient nuclei ; and any considerable amount of electrical discharge through the stratum would be the cause of the total distruction of the stratum. Thus we see that lightning discharges would not act in the way Gerdien describes; but, on the contrary, would be a hindrance rather than a help to the process on which the theory is based.

We are therefore forced to the conclusion that the lightning itself does not provide a source of ions for condensation to take place upon, and that we must depend upon the ascending currents of air to provide all the free ions for the separation of the electricity at the condensation layer.

Now we have already seen that under these circumstances we could not get lightning discharges from any given area of the storm more frequently than one during each hour. It must, however, be pointed out that even this frequency is far too high, for in order to discuss the most favourable circumstances we have assumed conditions which could not possibly take place in nature. We have assumed that every ion formed in the air as it passes from the lower clond through the supersaturated stratum continues to exist, and that complete separation of the ions takes place at the condensation layer, neither of which conditions could be fulfilled. Also we have neglected the whole loss of electricity due to any precipitation from the condensation layer, and further we have not taken into account the loss of electricity from the condensation layer which would take place through conduction in the great fields necessary to produce a lightning discharge. It would not perhaps be estimating these losses too high if we assumed that they would increase the intervals between two flashes ten times, and so make it only possible to have one flash in ten hours.

It thus appears that the theory does not account for the rapid electrical discharge observed in thunderstorms, and therefore in this respect it is unsatisfactory.

* C. Barus, Amer. Journ. Sci. xix. pp. 349-356, Nay 1905; and numerous later papers. 
(ii.) We will now consider the charge which rain formed in the condensation layer could carry to the earth with it. In order to treat again of the maximum effect possible we will assume that the whole water deposited in the condensation layer is deposited on the negative ions, and tbat every negative ion becomes the nucleus of a drop.

We will consider a cubic metre of air rising from the lower cloud to the condensation layer, where it deposits its water vapour on the negative ions which it contains.

We can accurately calculate the amount of water deposited under these conditions from a cubic metre of air. Let us assume that the temperature of the air on the ground is $25^{\circ} \mathrm{C}$., and that the height of the top of the lower cloud is 2,000 metres. Under these conditions the temperature of the air when it leaves the cloud will be about $15^{\circ} \mathrm{C}$., and the pressure approximately $600 \mathrm{~mm}$. From these initial conditions, according to the method described on pp. 122-124 of Professor J. J. Thomson's "Conduction of Electricity through Gases," we find that when condensation takes place at four-fold supersaturation 6.5 grams of water will be deposited from each cubic metre of air. Now if we know the number of ious on which this amount of water is deposited we can determine the quantity of electricity contained in each c.c. of water.

So far we have not found it necessary to determine how many ions are actually contained in the air when it reaches the condensation layer; we have only discussed the rate of formation of the ions, and this will not help us, for we do not know the upward velocity of the air, and so the time taken in traversing the supersaturated stratum. We must find the probable state of ionization from other considerations. Now at the surface of the earth numerous measurements of the ionization of the air have shown that under normal conditions a cubic metre of air contains about a quarter of an electrostatic unit of free electricity of each kind. From balloon ascents it has been found that this amount tends to increase as one rises from the surface, but for reasons given above it is very unlikely that the air in the supersaturation stratum would ever contain so many ions as have been found at the corresponding heights under normal conditions ${ }^{*}$. We will, however, for the sake of a round number, and in order to take the data used by Gerdien, assume that the air just before entering the condensation layer contains one electrostatic unit of each kind of electricity in the form of free ions. We shall then have approximately $3 \times 10^{9}$ ions of each

$$
\text { * L. c. pp. } 13 \text { and } 15 .
$$


kind in a cubic metre of air. Now, if every negative ion in the cubic metre of air receives some water, $6 \cdot 5$ grams of water will be deposited on 1 electrostatic unit of electricity, $i$. e. the charge per cubic centimetre of water will be $1 / 6 \cdot 5=\cdot 15$ electrostatic unit.

It is important to notice that this is the maximum charge per c.c. which it is possible for the water to obtain according to the theory, for we have assumed that every negative ion, in what must be granted to be highly ionized air, has been caught, and that only the water which has been deposited at the instant of condensation from four-fold supersaturation has condensed around the ions. We can even go further than this and say that not only is this the maximum charge possible, but that it would be a practical impossibility for the rain which reaches the earth to have so large a charge. The water which receives this maximum charge in the condensation layer has to fall through the whole of the lower cloud before it can reach the earth, and in the process it is bound to become mixed with a certain amount of uncharged water. Further, the lower cloud will itself be raining, so that the rain which reaches the earth will be a mixture of the charged precipitation from the condensation layer, and uncharged rain from the lower cloud. Thus, if rain is ever found to have as great a charge as $\cdot 15$ electrostatic unit per c.c. of water we shall be justified in asserting that the charge cannot possibly have been obtained in the manner which the theory supposes.

Turning now to the results of actual measurements, we find that Gerdien* records charges as large as $2 \cdot 25$ electrostatic units per gram of water: Weiss +5.3 units of negative and $13 \cdot 6$ units of positive electricity per gram of rain; and I myself have measured during rain in Simla charges as high as 19 electrostatic units of negative electricity per gram of rainwater. Thus it appears that in this particular also the theory signally fails to account for the observed facts.

(iii.) We will now turn to a still more important consideration and discuss the probability of any considerable separation of electricity taling place at the condensation layer.

To do this it will be necessary to go somewhat closely into the processes taking place at the condensation layer. We will imagine a volume of supersaturated air just arriving at the layer. Condensation takes place, and on the $3 \times 10^{9}$ negative ions in the cubic metre 6.5 grams of water are

* Gerdien, Jahrb. der Rad. und Elect. vol. i. p. 15 (1904).

$\dagger$ Weiss, Wien. Ber. cxv. pp. 1285-1320 (1906). 
condensed; now if each ion receives an equal share of this water the volume of each of the resulting water-drops will be $2.2 \times 10^{-9}$ c.c., and each drop will have a radius of $8 \times 10^{-3} \mathrm{~mm}$. According to the formula given by $\mathrm{Mr}$. Wilson, in the letter to 'Nature' which we are discussing, such drops will fall relatively to the air in which they are formed at the rate of $9 \mathrm{~mm}$. a second. Hence, if the air in the supersaturated stratum is rising with a greater velocity than this the drops will be carried upwards, and a cloud will form above the condensation layer.

It will at once be granted that the air must have a greater upward velocity than $1 \mathrm{~cm}$. a second, for if it had not it would take a given mass of air nearly 70 hours to pass from the lower cloud to the condensation layer above. Hence, over the condensation layer we shall have an ever-increasing cloud containing the greater part of the separated negative ions each bound to a water-drop. Now through this cloud all the positive ions will have to pass, and it is quite obvious that even if the cloud is only a few metres thick very few positive ions will pass out through its upper surface. Thus the cloud will not only contain the negative ions on which the water had been deposited, but it will also contain practically the whole of the corresponding positive charge; that is, little or no separation of electricity will take place.

The only escape from this reasoning is to assume that the number of ions in a cubic metre of air has been over-estimated, and that there are in reality so few ions present that drops large enough to fall immediately through the ascending current are formed. Such an assumption is perfectly valid, but it would only get over this difficulty by greatly increasing those treated of in (ii.) above and (v.) below.

It may be as well to point out here that the theory we are discussing is only partially based on experiment ; for although experiment has shown that when air is supersaturated to a fourfold degree condensation takes place on negative ions, no experiments have ever been made in which measurable quantities of electricity have been separated by the condensation process; until this has been done the theory cannot be said to be entirely satisfactory.

We will now pass on to discuss the theory from the meteorological point of view.

(iv.) In all the reasoning up to this point we have assumed the main proposition of the theory, namely, that the formation of a supersaturated stratum in the atmosphere is a possibility. Now it may not be possible to prove that the formation of a supersaturated stratum in the atmosphere would 
under all circumstances be an impossibility, but it is not difficult to show that we have here one of those cases in which the probability is so small that for practical purposes the word "improbable" may be replaced by "impossible."

The steps of the process leading up to the formation of dust-free air and then to a fourfold supersaturation have been so carefully described by Wilson and Gerdien that it is surprising to find that they both have left out of account a step which appears to be of vital importance to the theory; that is, the step by which the first few metres of the supersaturated stratum come into existence.

Wilson and Gerdien both commence their reasoning with a cumulus cloud ready formed, and having a supersaturated layer above it, into which more dust-free air is continually being passed from the cloud itself. We will start still further back in the history of the process, and consider the formation of the cloud and then of the supersaturated stratum.

Thunderstorms generally occur on warm calm days, and usually follow hot cloudless mornings. This is not always the case, but as we can only go into typical instances, it will be as well to consider a storm forming under some such conditions. We have, then, to start with a cloudless sky, and the air near the ground rapidly increasing in temperature as the day advances. First weak ascending currents form ; then as the ascending currents become stronger and penetrate higher condensation takes place at the upper surface of one of the more extensive of them. Thus a cumulus cloud is formed in dusty air with dusty air above it as well as below it. Now the ascending current will go on rising, and so will be continually pushing its way into the dusty air above. We will grant that the top of the ascending current is composed of air which has passed through the cloud, and is in consequence dust free, still it must be remembered that this air cannot push back the air around it without mixing with it to some extent, and so will have little chance of becoming supersaturated. Thus the dust-free air which rises from the cloud becomes contaminated with the surrounding dusty air, condensation takes place on it, and the cloud grows as fast as the ascending current rises. It may be urged that the first dust-free air which gets through the cloud may mix with the dusty air around, but that the resulting mixture may not be saturated; in this way a partition might be formed between the supersaturated air which subsequently passes out of the cloud and the dusty air above. This, however, neglects the fact that on account of the continuous rises there will always be ultimately, above the supersaturated air, 
a surface in which the air is both dusty and saturated, and in this layer condensation will take place. As soon as this occurs the drops will lag behind the ascending current, and will soon be overtaken by the region of supersaturated air. Drops thus fed by supersaturated air will grow more rapidly than the drops in the upper layer of the cloud below, and in consequence will lag behind the ascending current at a greater rate than the latter. Thus the supersaturated stratum which had begun to form will rapidly decrease in size and finally disappear, the top of the cloud becoming once more the boundary between the ascending air and dusty air which it is displacing.

In other words, an extensive supersaturated stratum could never form above an ascending current.

(v.) We will, however, for the sake of the discussion, assume that a supersaturated stratum may, as proposed by the theory, come into existence, and then consider whether such a stratum could exist during a thunderstorm.

It has been pointed out several times that in order to have a supersaturated stratum we must have a total absence of nuclei on which the water could condense. Now every drop of water which leaves the condensation layer has to pass through the supersaturated stratum on its way to the earth, and if the electrical discharges are to be as violent and frequent as we often observe during thunderstorms there must be a very considerable rainfall from the condensation layer. It must be admitted that each rain-drop as it passes through the supersaturated stratum will act as a very efficient nucleus for the condensation of the water vapour, and that no mass of air through which heavy rain is falling could long remain supersaturated.

Thus we see that a supersaturated stratum would be an impossibility underneath a condensation layer, condensing water at the rate necessary to bring into play the violent electrical discharges observed during thunderstorms. Hence, we are forced to conclude that the probability of the formation of an extensive supersaturated stratum in the atmosphere is extremely small, and that if even once formed it conld not long exist after precipitation commenced from the atmosphere above it.

(vi.) We will now turn to actual phenomena observed during thunderstorms, and see in how far they support the theory.

A peculiar formation for thunder-clonds is demanded by the theory: there must be a lower cloud to separate out the dust; then a dust- and clond-free supersaturated layer of 
considerable extent, which, if the storm is to last long, must be little less than 2,500 metres in vertical thickness; and, finally, a second cloud-layer where water is condensed on the negative ions, and the separation of electricity takes place.

From the time when the theory under consideration first came to my notice I have watched thunderstorms with special attention to the conditions which the theory presupposes. In no single case have I seen what appeared to be a large cumulus cloud with another cloud above it, but on the contrary, I have seen on several occasions distant clouds, from which heavy rain associated with thunder and lightning was falling, with sharply defined cumulus heads and quite clear sky above. Both Wilson and Gerdien refer to the false cirrus seen above thunder-clouds as very likely to be the cloud connected with the condensation layer. But every time that $I$ have seen a layer of cirrus-cloud accompanying a thunder-cloud it has appeared to me as if the top of the cumulus-cloud had reached a part of the atmosphere which had robbed it of its rounded form and spread it out into a cirro-stratus clond. I have never seen anything which would lead me to believe that between the heavy cumulus-cloud of the lower atmosphere and the cirro-stratus of the upper atmosphere there was a large cloudless region.

With regard to the electrical discharge of a thunderstorm; as far as my own observations go I sbould certainly say that the most violent and rapid discharges do not take place in the upper atmosphere: on the contrary they have always appeared to me to have their chief source in the centre of the large cumulo-nimbus cloud from which the rain was falling. The following account of a small thunderstorm may be interesting from the point of view of this theory. During an afternoon in August there had been heavy rain in Simla, but the sky commenced to clear betore six o'clock. Soon after the sky had cleared so far as to leave the hills around visible, with large masses of clouds still clinging to them in places, a cloud in the form of an isolated pillar of comparatively small cross-section was seen to be rapidly extending upwards. The cloud was evidently the result of a rapid rise of moist air in a local current; it extended upwards with a beautifully rounded cumulus boundary at the top, and the centre was seen to be illuminated at intervals of about a minute by vivid internal lightning discharges. In an hour the cloud had lost its shape and become an ill-defined mass of cloud. In this case it could be said with absolute certainty that there were not two clouds separated by a supersaturated 
layer, and, what is still more important, the cloud itself from base to summit during the time that the lightning-discharges were taking place was never 2,500 metres in height: thus supersaturation to a fourfold degree could not possibly have taken place.

To sum up the discussion, we may state that the following six reasons have been given for considering the theory, first proposed by Wilson, and subsequently expanded by Gerdien, unsatisfactory as an explanation of the electrical effects connected with thunderstorms.

\section{A. Electrical.}

(1) The theory does not account for the frequent lightning discharges observed during thunderstorms.

(2) It cannot account for the large charges of electricity carried down by rain during thunderstorms.

(3) It is extremely improbable that any electrical separation would take place as the result of water vapour being condensed from fourfold supersaturated air onto negative ions.

\section{B. Meteorological.}

(4) An extensive stratum of supersaturated air could not form above an ascending eurrent.

(5) Even if such a stratum were once formed it could not exist after precipitation commenced from the condensation layer above it.

(6) The meteurological phenomena observed during thunderstorms do not lend any support to the theory.

Simla, Nov. 11, 1908.

LVI. On Thunderstorm Electricity.

$B y$ C. T. R. WILson, M.A., F.R.S.*

MR. SIMPSON has been kind enough to send me a 11 copy of his paper "On the Wilson-Gerdien Theory of Thunderstorm Electricity."

I should like at the outset to remark that I have nowhere myself attempted to account for the strong electric fields of thunderstorms by the theory which Mr. Simpson attributes to me. I have merely regarded condensation on negative ions as one of the possible factors in the production of such fields.

* Communicated by the Author. 